\title{
The Effect of Reactance on Satisfaction: A Study in the Context of Supplementary Health Care Systems
}

\author{
Diego Nogueira Rafael ${ }^{1,+(1)}$ \\ ${ }^{1}$ Universidade Nove de Julho, São Paulo, SP, Brazil \\ Evandro Luiz Lopes ${ }^{2, \Omega(D}$ \\ ${ }^{2}$ Universidade Nove de Julho, Universidade Federal de São Paulo, São Paulo, SP, Brazil
}

\begin{abstract}
In a scenario in which the State is unable to serve the entire population, private health organizations have emerged, offering health plans and private assistance, called supplementary health systems. Given this context, the theme of this work is the study of the effect of psychological reactance on the satisfaction of users of supplementary health plans. The empirical phase was conducted through a survey with 145 university students. Data analysis, conducted through the macro PROCESS, indicated that the evaluation of supplementary health care providers is closely related to the level of individual reactance of the user and the way the plan is contracted. Furthermore, freedom of choice of the operator minimizes negative evaluations from individuals with high psychological reactance.
\end{abstract}

Keywords: psychological reactance; user satisfaction; providers.

\section{INTRODUCTION}

Psychological reactance is the negative emotional reaction to the loss of freedom, and it occurs when people feel that others are limiting their choices or their range of alternatives (Brehm \& Brehm, 1981; Van Petegem et al., 2015). This phenomenon is sensitive to the degree of direct coercive influence that the individual suffers. The greater the degree of influence, the greater the psychological reactance experienced.

According to Brehm and Brehm (1981), individuals generally react in an attempt to regain the freedom that was threatened, causing opposition to the agent responsible for reactance. Sometimes this reaction is expressed by aggression to the agent. On other occasions, it is expressed through greater attraction to the behavior that was threatened or the option that was lost. In either case, individuals with a high degree of reactance will make less positive evaluations of their current consumption options (Brehm \& Brehm, 1981; Mittal, 2015; Chatterjee, Chollet, \& Trendel, 2017).

Although the reactance theory has been widely studied in the field of cognitive psychology (Ungar et al., 2015, Lavoie et al., 2017), little is known about its effects on purchasing decision processes (Sittenthaler, Traut-Mattausch, \& Jonas, 2015) and in the evaluation of services (Lienemann \& Siegel, 2016; Wright, Agtarap, \& Mlynski, 2015). With this, the main theoretical contribution of this study is the identification of the role of psychological reactance in these behavioral processes.
Corresponding author:

† Universidade Nove de Julho, São Paulo, SP, Brazil

E-mail: diego_dnr@hotmail.com

${ }^{\Omega}$ Universidade Nove de Julho, Universidade Federal de São Paulo, São Paulo, SP, Brazil

E-mail: elldijo@uol.com.br

Received: 02/05/2018.

Revised: 03/04/2018.

Accepted: 04/06/2018

Published Online: 11/14/2018

DOI: http://dx.doi.org/10.15728/bbr.2019.16.2.1 
In order to identify the effect of psychological reactance on consumer behavior, especially in satisfaction with a service, we conducted a quantitative study, through a cross-sectional survey, with a sample of university students using supplementary health care plans of different types of contracting service - private plans and corporate plans. The data obtained were analyzed with the aid of the macro PROCESS, through which the moderating effect of psychological reactance on the satisfaction of the evaluator was identified.

Although end-of-life care - whether in hospitals, laboratories, or clinics - does not discriminate between private plans - which the individual joins by choice - and corporate plans - which the individual is included in simply due to being a member of an organization or association - the evaluation of this second group of health services is less positive when compared to the evaluation of the first group (Korschun, Bhattacharya, \& Swain, 2014). Possibly, the lack of freedom in contracting the plan results in a less positive evaluation when the employee of an organization uses the health services to which he or she is entitled. It is possible that psychological reactance can explain this difference in level of satisfaction.

The decision to use the supplemental health insurance sector as the setting for our study is also justified by its relevance in the current social context. Data from the National Health Agency (Agência Nacional de Saúde - ANS, 2017) indicate that more than 70 million Brazilians are users of supplementary health plans with different forms of adherence. The main ones are coercive (determined by the company in which the beneficiary works) and free choice (the beneficiary chooses which plan to purchase). Given this prominence, the supplementary health insurance sector earned more than 130 billion BRL (Brazilian currency) in 2016.

Customer satisfaction with health services is a key issue for the management of organizations. Satisfaction is increasingly being used as a key performance indicator for strategic and operational decision-making, directly reflecting the level of quality of services provided by the organization and at what level of quality it strives to achieve (Anderson, 1998; Milan \& Trez, 2005).

The study is presented in four sections, in addition to this brief introduction. The second section presents the theoretical pillars used to support the research. The following section highlights the method adopted in the empirical phase. The fourth section presents the results and, finally, the last section presents the considerations, suggestions for future studies, and the limits that surrounded the research.

\section{THEORETICAL FRAMEWORK}

In this section, the main theoretical pillars that guided this study will be discussed.

\subsection{Psychological Reactance}

The precursor of current psychological reactance studies stems from the work by Jack Brehm (Dowd, Milne, \& Wise, 1991). In his 1966 work entitled "A theory of psychological reactance", Brehm stated that the effect of reactance is diminished when the attempt to withdraw or limit freedom is subtle, collaborative, indirect, or justified. He also indicated that reactance is the appropriate theoretical paradigm to analyze and understand if the lack or limitation of freedom brings dissatisfaction to individuals.

Reactance is measured by the following assumptions: (i) extrapolation of the threat to current freedom to other freedoms, i.e., the person is in a scenario where his or her freedom is threatened and this situation threatens other freedoms of choice, which further increases the negative emotional state of the reactance; ii) the degree of direct threat to free behaviors, that is, the individual's level of motivational response will be proportionally greater when levels of threats to their state of freedom are higher; iii) the expectation regarding the freedom that the individual possessed, that is, if degree of freedom is suppressed, this will 
BBR

16,2

104

cause a greater impact in the reactance, otherwise, in a scenario where one had low expectations about freedom, the individual will not suffer greatly from the threat; and finally, iv) the importance of freedoms and free behaviors (Sittenthaler, Traut-Mattausch, \& Jonas, 2015; Ungar et al., 2015). The more important the behavior that is being threatened, the greater the degree of reactance consequently observed in the individual (Ungar et al., 2015; Lienemann \& Siegel, 2016).

When individuals encounter restrictions of their freedoms, whether in the form of a threat or a real fact, it presents a state of psychological reactance, a motivational state that drives the individuals to protect threatened freedoms (Santos, 2008; Chatterjee et al., 2017).

In a study published in the Journal of Consumer Marketing, examples were presented in which aggression and other acts of hostility manifested themselves when reactance occurred in consumer situations (Clee \& Wicklund, 1980). In those findings, consumers turned to their companies and employees to protect the freedom they thought was threatened in some way. Even if the manifestation of aggression is not perceived, consumer dissatisfaction, generated as a consequence of the lack or limitation of freedom, can generate less favorable evaluations than in a context in which psychological reactance is not present (Dowd et al. al., 1991; Chatterjee et al., 2017). That is, reactance has a direct impact on consumer satisfaction, and the higher the reactance, the lower the satisfaction (and vice versa).

Dowd et al. (1991) developed a psychometric scale, called TRS (Therapeutic Reactance Scale), to measure the level of psychological reactance of individuals. The proposed scale is composed of 28 items and presented good internal consistency and good predictive power.

Later, Buboltz, Thomas, and Donnell (2002) carried out a study with the objective of testing the TRS scale with a sample of 883 individuals, all graduate students from a university in the south of the United States of America. In this work, the authors identified four dimensions of psychological reactance, a) resentment of authority (resistance of the individual to be controlled by authoritarian figures), b) susceptibility to influence (when the individual is flexible to third party persuasion), c) exposure to conflicts (tendency of the individual to follow and agree with others to avoid disagreements), and d) preservation of freedom (individual desire to express opinions and have things adherent to beliefs). Even though the authors have stated that only a multidimensional measure can adequately represent the psychological reactance construct, most researches used one-dimensional reactance measurements (Mittal, 2015; Van Petegem et al., 2015; Stephen, 2016, Lavoie et al., 2017, among others).

\subsection{USER SATISFACTION}

Customer satisfaction is an important issue for organizations, managers, and researchers in general (Milan \& Trez, 2005), and this behavioral response is increasingly used as an indicator of performance, guiding operational and strategic decision-making, and consequently reflecting on the quality of service delivery throughout the organization (Gummesson, 2014).

For example, satisfaction corresponds to the measurement of one or more dimensions of users' opinions, which include assessments of the quality of services, the user's perception of their own clinical results, and overall satisfaction with the health services organization (Oliver, 1980).

Organizations with high levels of customer satisfaction have greater loyalty and retention (Orel \& Kara, 2014), consequently, ensuring greater financial returns for a longer time (Furse et al., 1994; Gummesson, 2014). Additionally, these companies are able to guarantee price elasticity, reduce costs with future renewals, and retain customers in moments of crisis (Bojei et al., 2013; Orel \& Kara, 2014). 
A previous study pointed out that, when there is a need to evaluate only the global satisfaction response, without concern for operational dimensions, the multiplicity of indicators model, such as Oliver (2014), which provides interesting elements, is recommended, since it associates the interchangeability in several situations with the objects studied (Marchetti \& Prado, 2001; Pastori Filho, 2004).

Using a theoretical perspective of psychological reactance in the evaluation of consumer satisfaction is not new. Fitzsimons (2000), with the support of Brehm's theory (1966), analyzed consumer reactions to the absence of inventories at the outlets of commercial establishments. In this study, Fitzsimons identified that individuals with low levels of psychological reactance were less affected by the lack of products and showed greater satisfaction with the establishment when compared to individuals with high reactance. However, it was not clear how the freedom of choice, or even the possibility of postponing the purchase, could affect the evaluation.

\subsection{HEALth INSURANCE PROVIDERS}

According to Law No. 9656 (1998), organizations, companies, or entities that administer activities to provide or commercialize insurance services or health care plans in Brazil are called health care plan operators.

The Brazilian supplementary healthcare system, which includes health plan operators, serves approximately 70.5 million citizens, equivalent to more than $30 \%$ of the population, and generated revenues of 131 billion BRL in 2016, representing 1,095 health plan operators (ANS, 2017).

The number of health service hires between 2015 and 2016 has shown a drop of $10.58 \%$ in the total number of beneficiaries throughout the supplementary health care system, which is justified by the unemployment rate in the country. According to IBGE - Brazilian Institute of Geography and Statistics (IBGE, 2016), the unemployment rate in the same period increased from $8.1 \%$ to $11.2 \%$, the highest rate since 2012 , when the counting started. When we observe the difference in relation only to medical care plans of the collective (coercive) type of business, the greatest reduction between the two periods is confirmed, with almost 887 thousand individuals no longer having the benefit, a reduction directly linked to the increase of unemployment. However, even considering this phenomenon, business plans still cover the majority of supplementary health users in Brazil.

The market for healthcare operators in Brazil is broad, with revenues of around 131 billion BRL in 2016, with 1,095 operators, and more than 52 thousand different health insurance options, divided between health care, dental care, or mixed. The total number of beneficiaries of the supplementary health system exceeds 69.9 million users, which roughly represents more than $30 \%$ of the total Brazilian population (ANS, 2017).

A considerable portion of the population seeks the assistance of supplementary health plans because of the difficulty in accessing the public health service and because they do not have the financial resources available to pay for private health care (Nelson et al., 1992; Gerschman et al., 2007; Braga et al., 2017).

Health plans have greater coverage in urban areas, with a higher rate among women and among those over 40 years of age, and their membership is growing, especially among higher income individuals. Coverage is greater for those who declare themselves with good or very good health, and lower for those who declare having poor health (Palma, 2006; Braga et al., 2017).

Health services began to be discussed more intensely in the second half of the 20th century, when studies began to evaluate health care with a focus on quality of care (Machado $\&$ Nogueira, 2008). Even so, the subject still raises great concern, both from managers and 
Table 1 - Beneficiaries by type of contract - Period: March / 2016.

\begin{tabular}{llll}
\hline Contract type & Health assistance & Only & Total \\
\hline Person or family & $9,558,718$ & $3,807,053$ & $13,365,771$ \\
Corporate collective & $32,412,727$ & $16,022,957$ & $48,435,684$ \\
Collective by membership & $6,561,881$ & $1,793,628$ & $8,355,509$ \\
Unidentified collective & 9,193 & 4,173 & 13,366 \\
Uninformed & 281,631 & 57,972 & 339,603 \\
\hline Total & $48,824,150$ & $21,685,783$ & $70,509,933$ \\
\hline
\end{tabular}

Source: Supplementary National Health Agency - ANS (2017)

academics, and is still far from being exhausted (Asubonteng, Mccleary, \& Swan, 1996; Mohammed et al., 2016).

It is already known that, to a large extent, supplementary health plans are contracted by companies and made available to employees as an additional benefit to the work remuneration package (Kochan et al., 2013). This scenario continues to increase, since several supplementary health care providers have stopped offering the plans directly to individuals, due to the regulation of the maximum readjustments stipulated by the National Health Agency (ANS, 2017) and have started making plans available only for legal entities (Mariano, 2014).

Table 1 shows that the total number of beneficiaries of the Brazilian supplementary health system who have coercive health plans (provided by the organizations in which they work) is $68.69 \%$, and the other health plans (subsidized by resources) serve only $31.31 \%$ of users.

\subsection{FORMULATION OF HYPOTHESES}

Here we present the hypotheses that guided the empirical phase of this study.

As was seen in the theoretical review, some studies have already identified that the lack of freedom of choice can negatively influence consumer satisfaction. We believe that, in the substantive context of this study, this relationship will be evidenced and, therefore, it is proposed:

H1 - There is a relationship between the type of health plan choice and user satisfaction. Specifically, we propose:

H1a - The satisfaction with the health plan will be greater when the user can choose the supplementary health care provider.

H1b - The satisfaction with the health plan will be lower when the user cannot choose the supplementary health care provider.

In addition, psychological reactance influences consumer satisfaction and, in the context of this study, can influence health plan user satisfaction. With this, we propose:

H2 - Reactance will moderate the relationship between the type of contract of the health plan and the satisfaction of the user.

Specifically:

H2a - High reactance will negatively influence user satisfaction when health plan choice is coercive.

H2b - Low reactance will positively influence user satisfaction when health plan choice is free.

The model to be tested is shown in Figure 1. 


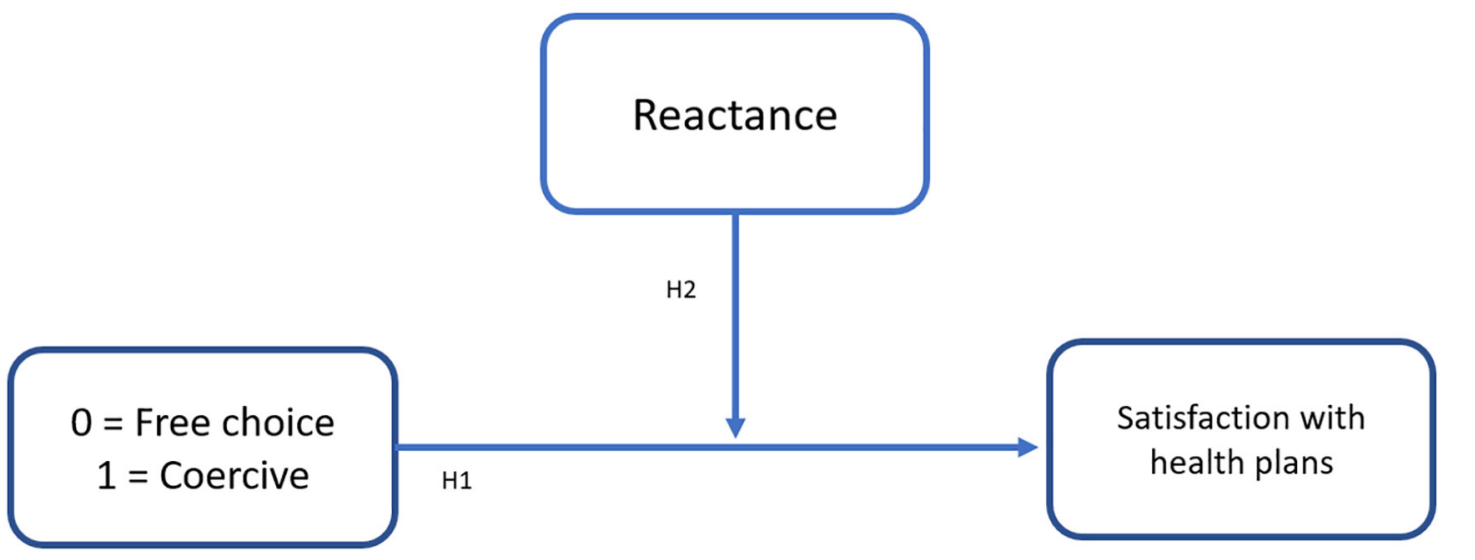

\section{METHOD}

In this section, we present the method that guided the empirical phase of this study.

\subsection{SAMPLE}

The sample used in this study was composed of university students from two higher education institutions - one public and the other private. The decision to use the students of both institutions was fundamentally due to the need of having a greater diversity of respondents, increasing the representativeness of the Brazilian context of adherence to the supplementary health plans. Even if access to the sample should be classified, in the Malhotra (2012) taxonomy, as a convenience sample, the main objective of the sample choice is to increase the external validity of the study (Cooper \& Schindler, 2016)

Even though there may be relative homogeneity of responses (Peterson, 2001), previous studies have already shown that samples composed of university students are adequate for consumer behavior research (Zimmermann \& Martinez-Pons, 1990; Peterson, 2001, \& Bryman, 2015).

\subsection{SCALES AND MEASURES}

We identified, through a direct question, the type of health plan contract used by the respondent. In this question, the participant indicated whether his/her health plan had been contracted directly (free choice) or if there was adhesion to a health plan contracted by the company with which the respondent maintained a labor bond (coercive choice).

We then asked the participants to evaluate their satisfaction with the health plan, using the scale proposed by Oliver (1980), with the items adapted to the context of this study. The statements are presented in Table 2.

In the third block of the data collection instrument, we estimated the psychological reactance of respondents through the TRS scale proposed by Dowd et al. (1991). The scale used is shown in Table 3.

Both satisfaction with the health plan and the respondent's psychological reactance were estimated using a 7-point Likert scale (anchored at $1=$ totally disagree and $7=$ totally agree). 
Table 2 - Items to measure satisfaction

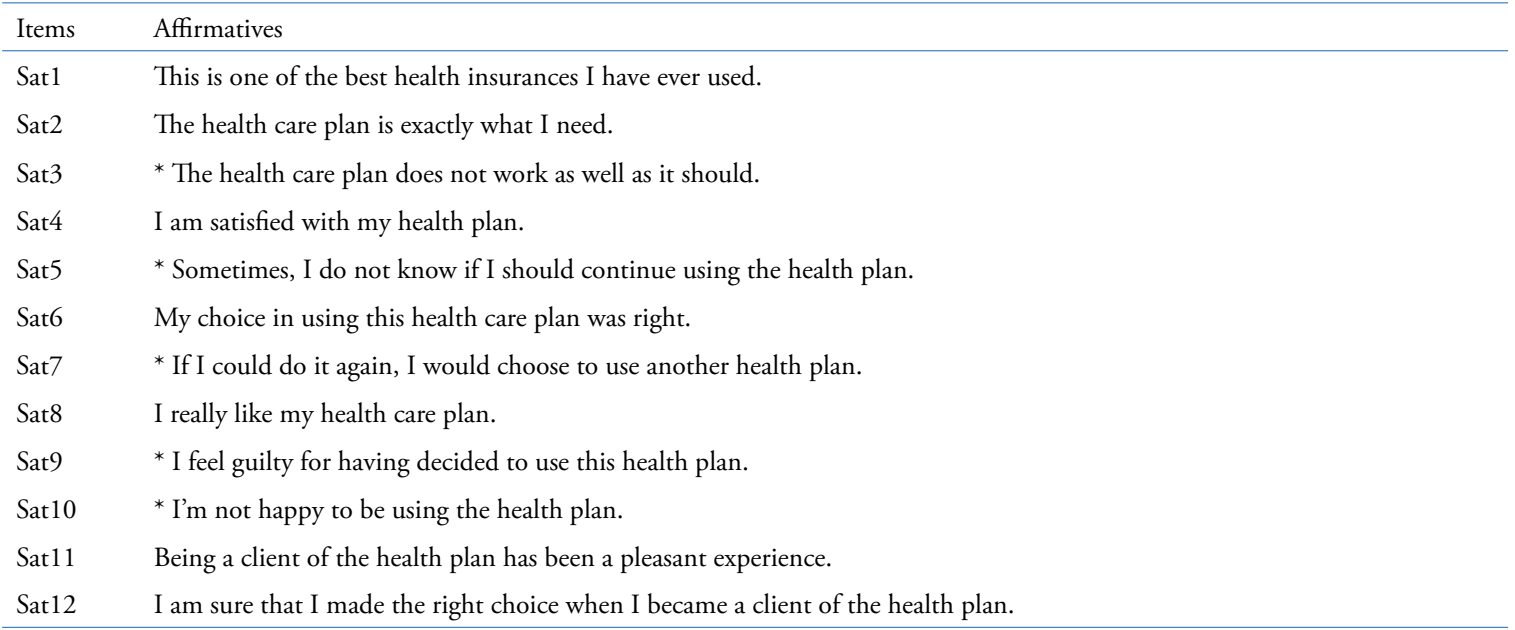

Note: the items with $\left(^{*}\right)$ are reverse.

Source: adapted from Oliver (1980)

Table 3 - Scale for measuring psychological reactance

\begin{tabular}{|c|c|}
\hline Items & Affirmatives \\
\hline Reat1 & * I do not mind changing my plans if someone in the group wants to do something else. \\
\hline Reat2 & *I do not mind when other people tell me what to do \\
\hline Reat3 & If someone asks me a favor, I think twice about what this person really wants. \\
\hline Reat4 & I'm not very tolerant of others' attempts to convince me. \\
\hline Reat5 & ${ }^{*}$ I am very open to other's offering solutions to my problems. \\
\hline Reat6 & *I do not mind doing something for someone, even if I do not know the reason I'm doing it. \\
\hline Reat7 & If I get a cold dish at a restaurant, I make a point of complaining about it. \\
\hline Reat8 & I have a strong desire to maintain my personal freedom. \\
\hline Reat9 & ${ }^{*}$ In discussions, I am easily persuaded by others. \\
\hline Reat 10 & * Sometimes I am afraid to disagree with others. \\
\hline Reat11 & I like discussions with other people. \\
\hline Reat12 & ${ }^{*}$ I often accept the suggestions of others. \\
\hline Reat13 & ${ }^{*}$ I usually accept the advice of others. \\
\hline Reat14 & I believe it is better to stand by what I believe than to be silent. \\
\hline Reat 15 & I like being a "devil's advocate" whenever I can. \\
\hline Reat16 & Nothing stimulates me as much as a good argument! \\
\hline Reat17 & I do have a lot of opinions. \\
\hline Reat 18 & It is important for me to be in a position of power before others. \\
\hline Reat19 & I like to confront people who think they're right. \\
\hline Reat20 & I consider myself to be more competitive than cooperative. \\
\hline Reat21 & I am very stubborn and firm in my thoughts. \\
\hline Reat22 & I do not like it when authorities try to tell me what to do. \\
\hline Reat23 & I see myself often questioning authorities. \\
\hline Reat24 & I like to see someone else do something that neither of us wants to do. \\
\hline Reat25 & It would be better to have more freedom to do what I want at work. \\
\hline Reat26 & If I am forced to do something, I often do the opposite. \\
\hline Reat27 & In fact, it bothers me when the cops impose on people what to do. \\
\hline Reat 28 & * It's very important that I get along with the people I work with. \\
\hline
\end{tabular}

Note: the items with $\left(^{*}\right)$ are reverse.

Source: adapted from Dowd et al. (1991). 
In order to verify the contract time of the services of the health plan of the respondent and the intensity of use of the agreement, questions were also presented on those subjects.

Finally, some demographic data were collected to characterize the sample.

\subsection{FIELD PROCEDURES}

The scales were presented to the participants by means of a questionnaire (in paper form) in the classroom. In advance, some care was taken, such as ensuring that there was no test or other evaluation activity on that day that would disrupt the routine of the respondents. It was still considered when there was some kind of adverse event such as bad weather, lack of electricity, among others.

Through the collection of personal and direct data (Malhotra, 2012), the survey was conducted in a cross-section (Malhotra, 2012; Cooper \& Schindler, 2016) and participants were instructed not to talk during the completion of the form, and were free to participate (or not) in the activity. We emphasize that, before conducting the survey, a pre-test with a reduced number of respondents $(n=5)$ was performed, indicating no changes were needed. The questionnaires completed in the pretest were discarded from the study.

\section{RESEARCH RESULTS}

The main objective of this section is to present the results found in the survey.

\subsection{Characterization OF THE SAMPLE}

At the data collection stage, 201 questionnaires were distributed and answered in two Brazilian universities, one private and one public. Of all respondents, $27.9 \%(n=56)$ were discarded because they did not have health insurance plans. These participants affirmed that they are users of the Unified Health System.

The valid sample $(n=145)$ consisted predominantly of women $(n=88,60.7 \%)$, and had an average age of 25 years $(\mathrm{SD}=3.32$ years $)$.

Among the respondents, 119 (82.1\%) claimed to engage in some gainful activity. Even though the sample was composed of regularly enrolled university students, four respondents $(2.8 \%)$ claimed to have completed a specialization course.

Most respondents $(77 \% ; \mathrm{n}=111)$ have a health plan provided by the companies in which they are employees (coercive option). The remaining respondents $(\mathrm{n}=35)$ have a health plan contracted directly and paid in full with personal resources (free choice).

According to the data, $11 \%$ of the valid sample $(n=14)$ has more than one health plan. Within this total, 101 respondents $(69.7 \%)$ declared to be holders of their health plans, while another 42 respondents $(29 \%)$ declared to be dependent.

Although 34 different health plan operators were identified for the valid sample, more than half of the participants are concentrated in only three $\left(50.3 \% ; \mathrm{n}=73 ; \mathrm{n}_{\text {Amil }}=30\right.$; $\mathrm{n}_{\text {Bradesco Saúde }}=27$ and $\mathrm{n}_{\text {Saúde Sulamérica }}=16$ ).

According to the responses, $13.1 \%(n=19)$ of the sample had one (or more than one) procedure denied by their supplemental health care provider.

\subsection{INITIAL ANALYSIS OF THE SATISFACTION SCALE WITH THE OPERATORS}

By means of an exploratory factorial analysis, conducted through orthogonal varimax rotation and principal component analysis (Hair et al., 2009), we observed the factorial unidimensionality of the items on the satisfaction scale, with explanatory power of $69.4 \%$ variance of the sample and adequate quality indicators $(\mathrm{KMO}=0.907$; Bartlett's sphericity test significant at the $1 \%$ level $\left.\left[\mathrm{c}^{2}{ }_{(28)}=753.24 ; \mathrm{p}<0.01\right]\right)$. 


\subsection{INITIAL ANALYSIS OF THE REACTANCE SCALE}

The exploratory factor analysis (EFA) of the reactance scale adapted from Dowd et al. (1991) indicated the need of eliminating three items due to low communality $\left(\mathrm{h}^{2}<0.5\right.$; Reat11, Reat18, and Reat19) and five items for cross-factor loading $\left(\mathrm{h}^{2}>0.5\right.$, Reat2, Reat7, Reat14, Reat21 and Reat28). In the second attempt, EFA identified a factor with an eigenvalue greater than 1, explaining $63.5 \%$ of the sample variance and with goodness of fit indicators, according to Hair et al. (2009) $(\mathrm{KMO}=0.706$; Bartlett's sphericity test significant at the $1 \%$ level $\left.\left[\mathrm{c}^{2}{ }_{(190)}=894.27 ; \mathrm{p}<0.01\right]\right)$. The internal consistency of the scale was also adequate $(\alpha=0.704)$.

\subsection{CONFIRMATORY FACTORIAL ANALYSIS OF THE SCALES}

Aiming to guarantee the theoretical robustness of the study, AFS performed a confirmatory factor analysis (AFC) in which the model of measurement of the set of variables was analyzed. In this phase, we seek to verify its convergent validity - how much the items of a latent construct explain its total variance, expressed by lambda matrices $(\lambda)$ greater than 0.60 , and also its discriminant validity, that is, how much the latent constructs are independent of each other, validity expressed by the values of the matrix phi $(\phi)$ lower than 0.60 (Anderson \& Gerling, 1988; Kline, 2005; Malhotra, Lopes, \& Veiga, 2014).

By this methodology, the models are considered appropriate when, in addition to the suitable convergent and discriminant validities, they present the CFI (Comparative Fit Index), GFI (Goodness of Fit Index), and NFI (Normed Fit Index) indexes above 0.90 and the RMR (Root Mean Square Residual) standardized lower than 0.05 (Kline, 2005), and the RMSEA (Root Mean Square Error of Approximation) presents a coefficient less than 0.08 for a reasonable adequacy or less than 0.05 for a good adaptation (Anderson \& Gerbing, 1988; Malhotra, Lopes, \& Veiga, 2014).

With the use of Lisrel 8.72, we confirmed the factorial constitution of the scales found in the exploratory phase. All loads $(\lambda)$ presented adequate indicators (between 0.652 and 0.993 ), guaranteeing the convergent validity and the phi matrix, lower than 0.60 , suggesting good discriminant validity between the satisfaction and reactance constructs. In addition, the goodness of fit indicators were satisfactory $\left(\mathrm{c}^{2} / \mathrm{df}=3.28, \mathrm{RMSEA}=0.04, \mathrm{CFI}=0.98\right.$, $\mathrm{NFI}=0.96, \mathrm{GFI}=0.96$ and $\mathrm{RMSR}=0.02$ ). Figure 2 presents the results of this analysis.

As all measurements were made on the basis of a self-completion form, and the data were collected simultaneously in a cross-sectional time (Malhotra, 2012), it is possible that a variance common to the method occurred (Williams, \& Brown, 1994; Podsakoff et al., 2003; Craighead et al., 2011). Considering a bias in the measurement of psychometric scales, the common method variance (CMV, from this point on) may cause errors in the estimation of causal relationships, inflating or underestimating the relationships between the constructs resulting in errors of both type I and type II (Richardson, Simmering, \& Sturman, 2009; Craighead et al., 2011). Even though the operation of data collection has reduced the possibility of CMV occurrence, because there was randomization in the presentation of the dependent and independent variables, and we also guaranteed anonymity to the research participants, methodological procedures do not always guarantee the eradication of this bias.

In order to mitigate this doubt, we conducted Harman's unique factor test (Podsakoff et al., 2003, Richardson, Simmering, \& Sturman, 2009), which consists in the realization of a major non-rotated component EFA in which all indicators are grouped into a single dimension. The literature indicates that Harman's single-factor test is the most used to verify CMV (Podsakoff et al., 2003), probably due to the simplicity of its operation. By this methodology, there is a belief that the effect of CMV is not significant if the total variance explained by the single non-rotated factor is less than $50 \%$ of the total variance of the scale. 


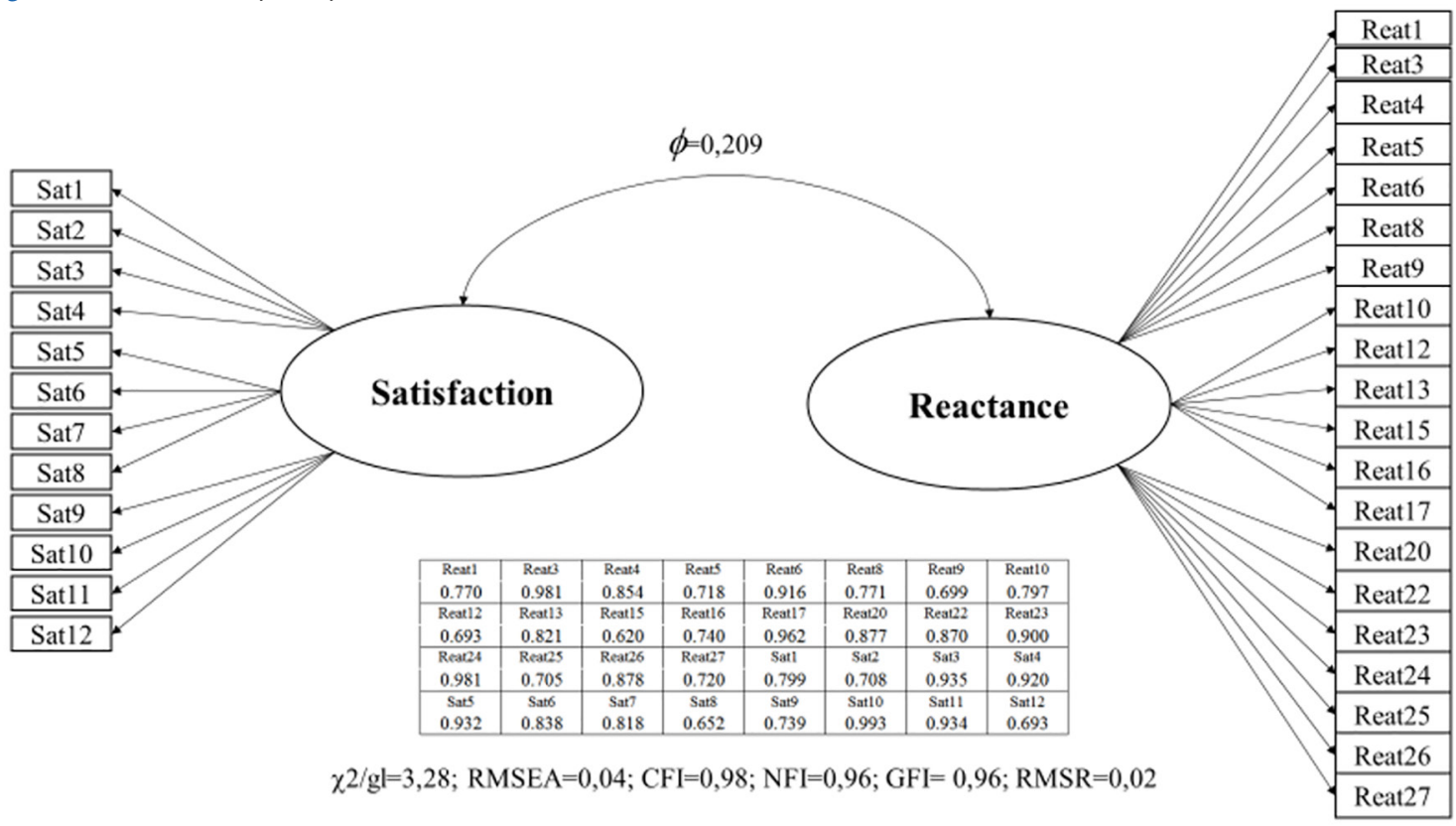

As the generated factor presented explained variance of $39.27 \%$, lower than the critical limit of the test (50\%), we conclude that the study does not suffer from this bias.

Considering these results, we proceed with the analysis of the research data.

\subsection{DESCRIPTIVE ANALYSIS OF OPERATOR SATISFACTION}

Given the one-dimensional characteristic of the scales, the satisfaction declared by the respondents was aggregated through the average of the items of the Oliver scale (1980) $(\alpha=0.764)$. The operator with the lowest score in this construct was Saint Helena (Average $=1.5$ ). The operators with the highest scores were Saúde Caixa and Omint, both with the maximum score $(\mathrm{M}=7)$, but it is worth mentioning that each one received only one evaluation. The mean sample satisfaction was $4.74(\mathrm{SD}=1.65)$.

Among the three health operators with the highest concentration of respondents, Sulamérica $(M=5.45)$ and Bradesco Saúde $(M=5.42)$ were above the mean of reported satisfaction, while Amil $(\mathrm{M}=4.7)$, which ranks first in the number of sample users, remained slightly below average satisfaction. Figure 3 shows the satisfaction declared by the users in relation to the 34 health operators.

\subsection{REGRESSIVE ANALYSIS AND MODERATION TEST}

In order to verify the direct effect of the type of operator choice (coercive versus free) and the possible effect of moderation of the respondent reactance in this relation, we used model 1 (simple moderation) of the PROCESS macro (Hayes, 2013). For this, we used a dummy variable for the type of operator choice - assigning " 0 " for the cases in which the choice was free and " 1 " for the cases in which the choice of the operator of the plan was decided by the company. The use of PROCESS for the analysis of moderation is justified by the increasing use of this technique in applied social sciences and psychology studies given its great versatility and ease of interpretation of complex relational models. In addition, this technique of data analysis has been widely used in consumer behavior surveys published in international journals of high impact factor (Prado, Korello, \& Silva, 2014).

The regressive model found a direct and negative effect between the type of plan contraction and the stated satisfaction $\left(\beta=-2.223,95 \%\right.$ CI $\left.[-3.880,-0.567], \mathrm{t}_{(136)}=-2.655, \mathrm{p}<0.01\right)$. 
BBR

16,2

112

Figure 3 - Health operator declared by the consumers

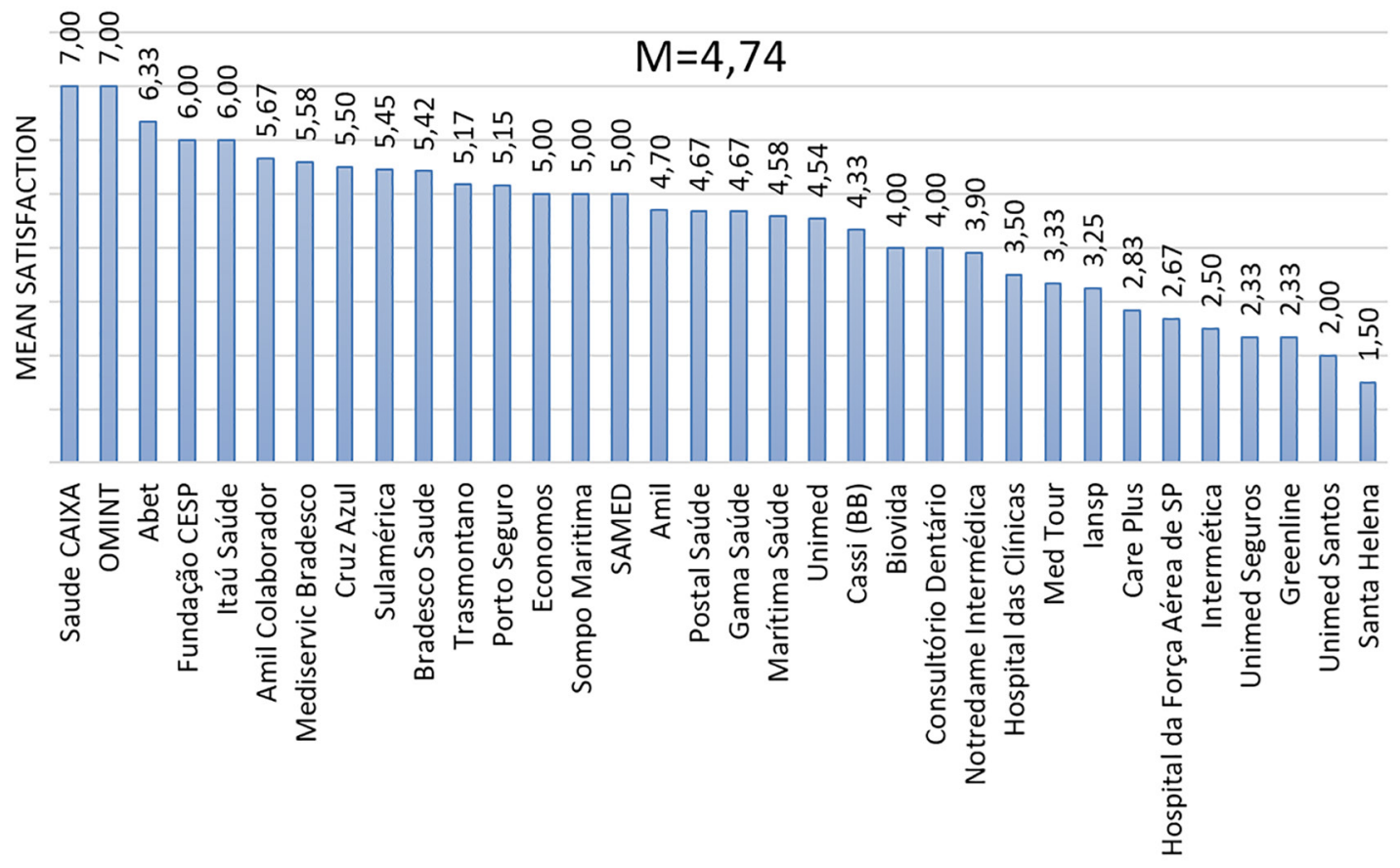

It also identified a negative effect between psychological reactance and respondent satisfaction $\left(\beta=-0.592,95 \% \mathrm{CI}[-0.755,-0.322], \mathrm{t}_{(136)}=-4.929, \mathrm{p}<0.01\right)$. Finally, the model identified the positive effect of reactance moderation on the relationship between the type of hiring and the satisfaction declared by the respondent ( $\beta=0.667,95 \% \mathrm{CI}[0.228,1.106]$, $\left.\mathrm{t}_{(136)}=3.008, \mathrm{p}<0.01\right)$. These results are shown in Figure 4.

The results indicated that respondents demonstrate higher levels of satisfaction when the choice of supplementary health care provider occurs freely, while satisfaction levels are lower when the choice is coercive. They also indicated that reactance exerts a positive moderation in this relationship. Therefore, it is possible to admit that higher levels of individual psychological reactance worsen satisfaction indicators in cases of coercive choice of supplementary health care workers, while lower levels of individual psychological reactance minimize this effect.

At the end of the analysis phase, we conducted the Jonhson-Neyman test (Hayes, 2013; Hayes \& Montoya, 2017), with the purpose of analyzing in detail the effect of moderation of psychological reactance. The result of this phase is shown in Figure 5.

We identify two points in which the significance of moderation occurs. For low levels of individual psychological reactance (less than 2.06), coercive plans give rise to greater satisfaction when compared to free choice plans. On the other hand, high levels of individual psychological reactance (above 4.21) in relation to coercively adopted plans give rise to lower levels of satisfaction than freely chosen plans. For median levels of individual psychological reactance $(2.06<$ Reactance $<4.21)$, there is no significant difference in stated satisfaction, regardless of the type of contract.

With this result, it is possible to propose that the level of satisfaction declared is not only associated with the type of contract of the plan, but also, and to a great extent, that satisfaction is explained by individual psychological reactance.

Finally, for cases in which the choice of the supplementary health care provider was free, the individual reactance level has no influence on the stated satisfaction. For any level of reactance, the satisfaction was always the same. 


\section{DISCUSSION OF RESULTS}

The findings of this study are in line with previous studies (Furse et al., 1994; Santos, 2008; Chatterjee et al., 2017), regarding the consequences of lack of freedom in hiring supplementary health care providers. We identified a direct effect between the type of hiring and satisfaction manifested by the sample. The results indicate that the free choice of the operator results in higher levels of general satisfaction, while reducing this freedom results in more moderate levels of satisfaction.

In addition to the previous studies that analyzed the psychological reactance (Brehm \& Brehm, 1981; Korschun et al., 2014; Van Petegem et al., 2015), there was a moderation effect between this personality trait and the relationship between the type of hiring of supplementary health care providers and consumer satisfaction with them. There is evidence that high individual psychological reactance results in greater negative effect between coercive plans and satisfaction. Likewise, low levels of psychological reactance result in more favorable evaluations in the same context. This finding points to an issue that is not yet on the agenda of the operators' managers. Lack of freedom, per se, will result in lower levels of satisfaction, regardless of the actual quality of the operation, at least for a portion of users (individuals with high reactance levels).

In fact, the type of hiring of the operator already explains a portion of the stated satisfaction. However, our study identified that the respondent's psychological reactance influences this relationship. When the reactance is higher, there is a reduction of individual satisfaction.

Figure 4 - Regressive Model

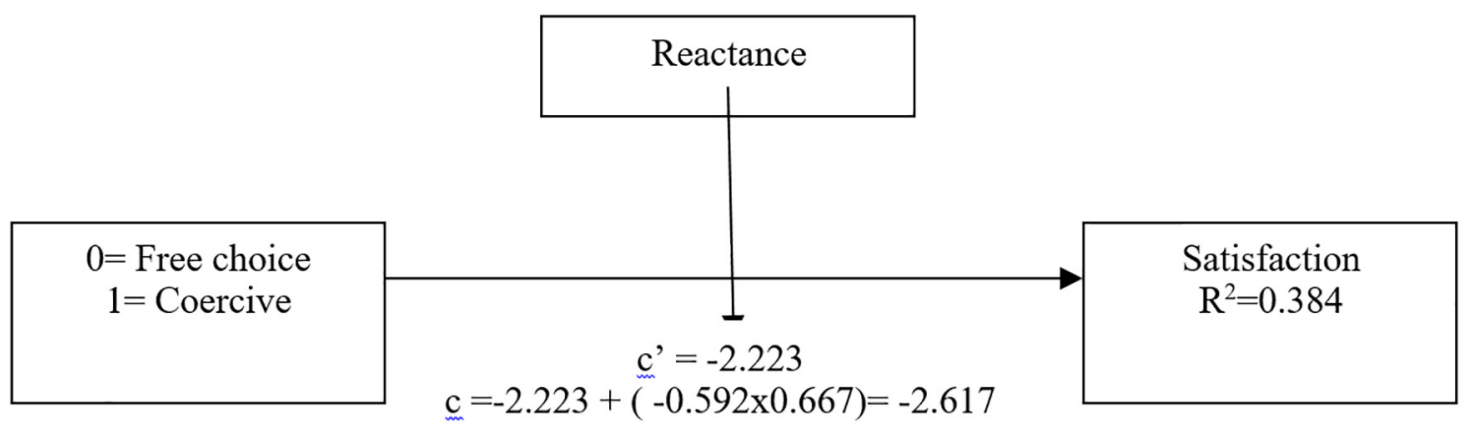

Figura 5 - Analysis of moderation of psychological reactance in satisfaction

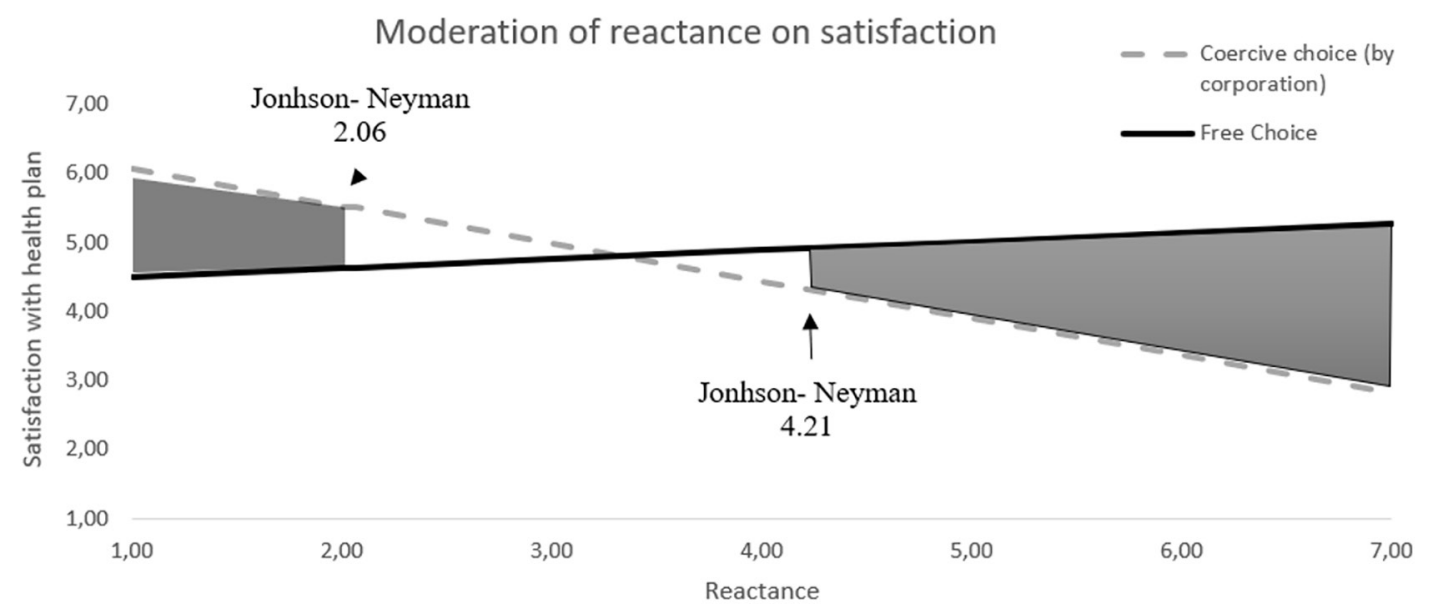


BBR

16,2

114

An interesting aspect, identified through this study, is the maintenance of levels of consumer satisfaction, regardless of their levels of reactance, when the choice of the supplementary health care provider is an individual and free decision.

\subsection{Managerial CONTRIBUtions}

Of course, much of the user satisfaction for the supplementary health services was not explained by the constructs measured in this study. After all, the estimated coefficient of determination indicates that approximately $38 \%$ of the declared satisfaction is the result of the type of contracted plan and the psychological reactance of the respondent. With this, it is certain that a great part of the satisfaction of the users is related to other factors, such as the quality of the services, the readiness in the consultations, and the accuracy of the diagnoses, among other aspects. Therefore, it is of the utmost importance that managers of supplementary health care providers make efforts to ensure the minimum standards required by consumers.

On the other hand, as there is evidence that levels of individual psychological reactance strongly influence user satisfaction, when hiring is not supported by freedom of choice, it is reasonable to assume that the provision of some "service package" options for choice of users, even in contexts of coercive acquisition, is a way of offering greater psychological comfort, which may result in higher levels of user satisfaction.

Likewise, human resource managers, who hire additional health care providers for their companies, can use the simultaneous offer of more than one operator as a strategy to increase user satisfaction levels. With this, even if the operators are equivalent, the greater freedom of choice will contribute to the elevation of the levels of individual satisfaction.

\subsection{TheOretical CONTRIBUTIONS, LIMITS AND SUGGESTIONS FOR FU- TURE STUDIES}

One of the contributions of this study is the adaptation of the satisfaction scale (Oliver, $1980)$ to the context of health services. Also on the construct operations, another contribution is the use of the individual psychological reactance scale (Dowd et al., 1991) for the service consumption scenario.

The main theoretical contribution of this work is the identification of the effect of the moderation of individual psychological reactance in the context of coercive consumption. In fact, the test and confirmation of the hypotheses suggested allowed identification of the effects of reactance, at different levels. To the best of our knowledge, this effect, with this level of detail, had not yet been empirically demonstrated.

As in all academic papers, several boundaries surrounded this study. One was the sample size. Even if our sample was adequate to meet the rigor required by the statistical tests, it was not possible, for example, to make an individual analysis of the supplementary health care providers studied. Another point of attention, also limited by sample size, was the impossibility of studying how the phenomenon occurs when the respondent is the contractor or when he is one of the dependents of the plan. In this sense, our recommendation is to replicate this study in other more robust samples.

Another suggestion for the continuity of the studies of this theme is the comparative analysis between the effect of individual psychological reactance of users of supplementary health plans and users of the Unified Health System (SUS). The current public health policy does not provide users with any freedom. Even in primary care, the citizen is welcomed in the public apparatus that is closest to his or her residence and, therefore, does not have any degree of freedom of choice for simple procedures. Possibly, a portion of the lowest theoretical satisfaction of SUS users can be explained by the psychological reactance of the respondents, and not only by the tacit attributes of the service experienced. 
At the end of this work, we took the liberty of showing that our motivation was to initiate a successful discussion of the effect of a long-identified personality trait in the context of health services. Obviously, it was not our intention to exhaust this theme, but rather to inspire other researchers to make efforts in the construction of a research agenda on the psychological reactance in consumption. We hope that this goal has been achieved.

Note: the authors are grateful for the excellent suggestions of improvement received from the anonymous reviewers and BBR editors.

\section{REFERENCES}

Agência Nacional de Saúde Suplementar. ANS: quem somos. Access in April, 01/2017, in: http://www.ans. gov.br/aans/quem-somos. 2017.

Anderson, E. W. (1998). Customer satisfaction and word of mouth. Journal of service research, 1(1), 5-17.

Anderson, J. C., \& Gerbing, D. W. (1992). Assumptions and comparative strengths of the two-step approach: Comment on Fornell and Yi. Sociological Methods \& Research, 20(3), 321-333.

Asubonteng, P., McCleary, K. J., \& Swan, J. E. (1996). SERVQUAL revisited: a critical review of service quality. Journal of Services marketing, 10(6), 62-81.

Bojei, J., Julian, C. C., Wel, C. A. B. C., \& Ahmed, Z. U. (2013). The empirical link between relationship marketing tools and consumer retention in retail marketing. Journal of Consumer Behaviour, 12(3), 171-181.

Braga, S. F. M., Souza, M. C. D., Oliveira, R. R. D., Andrade, E. I. G., Acurcio, F. D. A., \& Cherchiglia, M. L. (2017). Revista de Saúde Pública. Revista de saude publica, 51, 46.

BREHM, Sharon S.; BREHM, Jack W. (1981). Psychological Reactance: A Theory of Freedom and Control. Academic Press.

Bryman, A., \& Bell, E. (2015). Business research methods. Oxford University Press, USA.

Buboltz, W. C., Thomas, A., \& Donnell, A. J. (2002). Evaluating the factor structure and internal consistency reliability of the therapeutic reactance scale. Journal of Counseling \& Development, 80(1), 120-125.

Chatterjee, P., Chollet, B., \& Trendel, O. (2017). From conformity to reactance: Contingent role of network centrality in consumer-to-consumer influence. Journal of Business Research, 75, 86-94.

Clee, M. A., \& Wicklund, R. A. (1980). Consumer behavior and psychological reactance. Journal of Consumer Research, 6(4), 389-405.

Cooper, D. R., \& Schindler, P. S. (2016). Métodos de Pesquisa em Administração-12 ${ }^{a}$ Edição. McGraw Hill Brasil.

Craighead, C. W., Ketchen, D. J., Dunn, K. S., \& Hult, G. T. M. (2011). Addressing common method variance: guidelines for survey research on information technology, operations, and supply chain management. IEEE Transactions on Engineering Management, 58(3), 578-588.

Dowd, E. T., Milne, C. R., \& Wise, S. L. (1991). The Therapeutic Reactance Scale: A measure of psychological reactance. Journal of Counseling \& Development, 69(6), 541-545.

Pastori Filho, O. (2004). A percepção de valor do consumidor frente ao recall de veículos no Brasil: um estudo exploratório em São Paulo (Doctoral dissertation).

Fitzsimons, G. J. (2000). Consumer response to stockouts. Journal of consumer research, 27(2), 249-266.

Furse, D. H., Burcham, M. R., Rose, R. L., \& Oliver, R. W. (1994). Leveraging the value of customer satisfaction information. Marketing Health Services, 14(3), 16.

Gerschman, S., Veiga, L., Guimarães, C., Ugá, M. A. D., Portela, M. C., Vasconcellos, M. M., ... \& Lima, S. M. L. (2007). Estudo de satisfação dos beneficiários de planos de saúde de hospitais filantrópicos. Ciência \& saúde coletiva, 12, 487-500.

Gummesson, E. (2014). Productivity, quality and relationship marketing in service operations: A revisit in a new service paradigm. International Journal of Contemporary Hospitality Management, 26(5), 656-662.

Hair, J. F., Black, W. C., Babin, B. J., Anderson, R. E., \& Tatham, R. L. (2009). Análise multivariada de dados. Bookman Editora.

Hayes, A. F. (2017). Introduction to mediation, moderation, and conditional process analysis: A regressionbased approach. Guilford Publications.

Hayes, A. F., \& Montoya, A. K. (2017). A tutorial on testing, visualizing, and probing an interaction involving a multicategorical variable in linear regression analysis. Communication Methods and Measures, 11(1), $1-30$.

Kline, R. B. (2015). Principles and practice of structural equation modeling. Guilford publications. 
BBR

16,2

116

Kochan, T. A., Eaton, A. E., McKersie, R. B., \& Adler, P. S. (2013). Healing together: The labor-management partnership at Kaiser Permanente. Cornell University Press.

Korschun, D., Bhattacharya, C. B., \& Swain, S. D. (2014). Corporate social responsibility, customer orientation, and the job performance of frontline employees. Journal of Marketing, 78(3), 20-37.

LaVoie, N. R., Quick, B. L., Riles, J. M., \& Lambert, N. J. (2017). Are graphic cigarette warning labels an effective message strategy? A test of psychological reactance theory and source appraisal. Communication Research, 44(3), 416-436.

LAW n 9.656, June, 03/1998 (1998). Provides for private health insurance plans and insurances. Brasília, DF. Access in April, 01/2016 from http://www.planalto.gov.br/ccivil_03/leis/L9656.htm.

Lienemann, B. A., \& Siegel, J. T. (2016). State psychological reactance to depression public service announcements among people with varying levels of depressive symptomatology. Health communication, 31(1), 102-116.

Machado, N. P., \& Nogueira, L. T. (2008). Avaliação da satisfação dos usuários de serviços de Fisioterapia. Revista Brasileira de Fisioterapia, 12(5).

Malhotra, N. K. (2012). Pesquisa de marketing: uma orientação aplicada. Bookman Editora.

Malhotra, N. K., Lopes, E. L., \& Veiga, R. T. (2014). Modelagem de equações estruturais com Lisrel: uma visão inicial. REMark, 13(2), 27.

Marchetti, R., \& Prado, P. H. (2001). Um tour pelas medidas de satisfação do consumidor. Revista de administração de empresas, 41(4), 56-67.

Mariano, F. G. Consumidores encontram dificuldades para aderir a plano de saúde individual. ZH Economia. In: http://zh.clicrbs.com.br/rs/noticias/economia/noticia/2014/08/consumidores-encontram-dificuldades-para-aderir-a-plano-de-saude-individual-4571765.html. Access in April, 14th/2017.

Milan, G., \& Trez, G. (2005). Pesquisa de satisfação: um modelo para planos de saúde. RAE-eletrônica, 4(2).

Mittal, B. (2015). Self-concept clarity: Exploring its role in consumer behavior. Journal of Economic Psychology, 46, 98-110.

Mohammed, K., Nolan, M. B., Rajjo, T., Shah, N. D., Prokop, L. J., Varkey, P., \& Murad, M. H. (2016). Creating a patient-centered health care delivery system: a systematic review of health care quality from the patient perspective. American Journal of Medical Quality, 31(1), 12-21.

Nelson, E. C., Rust, R. T., Zahorik, A., \& Rose, R. L. (1992). Do patient perceptions of quality relate to hospital financial performance?. Marketing Health Services, 12(4), 6.

Oliver, R. L. (1980). A cognitive model of the antecedents and consequences of satisfaction decisions. Journal of marketing research, 460-469.

Oliver, R. L. (2014). Satisfaction: A behavioral perspective on the consumer. Routledge.

Orel, F. D., \& Kara, A. (2014). Supermarket self-checkout service quality, customer satisfaction, and loyalty: Empirical evidence from an emerging market. Journal of Retailing and Consumer Services, 21(2), 118129.

Palma, J. J. L. (Coord.) (2006). Painel de Indicadores do SUS. Brasília: Secretaria de Gestão Estratégica e Participativa / Ministério da Saúde.

Peterson, R. A. (2001). On the use of college students in social science research: Insights from a second-order meta-analysis. Journal of consumer research, 28(3), 450-461.

Prado, P. H. M., Korelo, J. C., \& Silva, D. M. L. (2014) Análise de mediação, moderação e processos condicionais. REMark- Revista Brasileira De Marketing, v. 13, n. 4.

Podsakoff, P. M., MacKenzie, S. B., Lee, J. Y., \& Podsakoff, N. P. (2003). Common method biases in behavioral research: A critical review of the literature and recommended remedies. Journal of applied psychology, 88(5), 879 .

Richardson, H. A., Simmering, M. J., \& Sturman, M. C. (2009). A tale of three perspectives: Examining post hoc statistical techniques for detection and correction of common method variance. Organizational Research Methods, 12(4), 762-800.

Santos, R. C. (2008). Um estudo sobre o valor e a reatância nas reações dos consumidores brasileiros frente ao recall de produtos. GVPESQUISA Relatório, 3.

Sittenthaler, S., Traut-Mattausch, E., \& Jonas, E. (2015). Observing the restriction of another person: vicarious reactance and the role of self-construal and culture. Frontiers in psychology, 6, 1052.

Stephen, A. T. (2016). The role of digital and social media marketing in consumer behavior. Current Opinion in Psychology, 10, 17-21.

Ungar, N., Sieverding, M., Schweizer, F., \& Stadnitski, T. (2015). Intervention-elicited reactance and its implications: Let me eat what I want. Zeitschrift für Psychologie, 223(4), 247. 
Van Petegem, S., Soenens, B., Vansteenkiste, M., \& Beyers, W. (2015). Rebels with a cause? Adolescent defiance from the perspective of reactance theory and self-determination theory. Child Development, 86(3), 903-918.

Williams, L. J., \& Brown, B. K. (1994). Method variance in organizational behavior and human resources research: Effects on correlations, path coefficients, and hypothesis testing. Organizational Behavior and Human Decision Processes, 57(2), 185-209.

Wright, R. A., Agtarap, S. D., \& Mlynski, C. (2015). Conversion of Reactance Motives Into Effortful Goal Pursuit. Zeitschrift für Psychologie.

Zimmerman, B. J., \& Martinez-Pons, M. (1990). Student differences in self-regulated learning: Relating grade, sex, and giftedness to self-efficacy and strategy use. Journal of educational Psychology, 82(1), 51. 